\title{
Retraction Note: A novel method of augmenting gene expression and angiogenesis in the normal and ischemic canine myocardium
}

Qiao-Ying Yuan - Zheng-Wei Zhu •

Zhang Wang • Xiao-Mei Wang • Xing-Sheng Li •

Jing Huang $\cdot$ Liang-Yi Si

Published online: 25 April 2013

(C) Springer Japan 2013

Retraction to: Heart Vessels (2012) 27:316-326

DOI 10.1007/s00380-011-0165-x

The article "A novel method of augmenting gene expression and angiogenesis in the normal and ischemic canine myocardium. Heart Vessels. 2012 May;27(3):316-326." has been retracted due to duplicate publication.

The online version of the original article can be found under doi:10.1007/s00380-011-0165-x.

Q.-Y. Yuan · Z. Wang · X.-M. Wang · L.-Y. Si $(\bowtie)$

Department of Geriatrics, Southwest Hospital,

Third Military Medical University, Gao Tan Yan Street,

Sha Ping Ba District, Chongqing 400038,

People's Republic of China

e-mail: siliangyi66@163.com

\section{Z.-W. Zhu}

College of Civil Engineering of Chongqing University,

Key Laboratory of New Technology for Construction of Cities in Mountain Area (Chongqing University), Ministry of Education,

Chongqing 400045, People's Republic of China

X.-S. Li · J. Huang

Institute of Ultrasound Imaging,

Chongqing University of Medical Sciences,

Chongqing 400010, People's Republic of China 